\title{
Immunolocation of Aquaporin 8 in Human Cataractous Lenticular Epithelial Cells
}

\author{
Rijo Hayashi $^{a}$ Shimmin Hayashi ${ }^{b}$ Kazunori Fukudac ${ }^{c}$ Miki Sakai ${ }^{a}$ \\ Shigeki Machida ${ }^{a}$ \\ a Department of Ophthalmology, Koshigaya Hospital, Dokkyo Medical University, \\ b Department of Ophthalmology, Koshigaya Hospital, Dokkyo Medical University, Lively \\ Eye Clinic, and 'Koshigaya Hospital Joint Research Center, Dokkyo Medical University, \\ Koshigaya, Japan
}

\section{What Is It about?}

Aquaporin 8 (AQP8) is a diffusion facilitator of hydrogen peroxide through cell membranes. This is the first investigation confirming the presence of AQP8 in human lenticular epithelial cells (LECs). Lenticular anterior capsule samples, including LECs, were collected during cataract surgery of cataract patients after informed consent. Immunohistochemical staining of AQP8 was observed surrounding and within the cytoplasm of LECs. RT-PCR and gel electrophoresis also revealed the presence of AQP8 mRNA in the lenticular anterior capsule. The results of immunohistochemical staining were comparable to those of RT-PCR and gel electrophoresis.

\section{Keywords}

Aquaporin $8 \cdot$ Human lenticular epithelial cells $\cdot$ Hydrogen peroxide $\cdot$ Immunohistological staining $\cdot$ Real-time polymerase chain reaction

\section{Abstract}

Purpose/Aim: Aquaporin 8 (AQP8) is a diffusion facilitator of hydrogen peroxide $\left(\mathrm{H}_{2} \mathrm{O}_{2}\right)$ through cell membranes. The purpose of this study was to confirm and localize AQP8 in human lenticular epithelial cells (LECS). Materials and Methods: Lenticular anterior capsule samples, including LECs, were collected during cataract surgery of cataract patients after informed consent. The localization of AQP8 was detected by immunohistochemical staining using an antibody to AQP8. Real-time polymerase chain reaction (RT-PCR) was also used to determine the AQP8 mRNA expression levels. The PCR products were analyzed by gel electrophoresis following analyses of band density. Results: Immunohistochemical staining showed AQP8 was distributed throughout the whole area of the anterior capsulotomy. AQP8 labeling was observed surrounding and within the cytoplasm of LECs. RT-PCR and gel electrophoresis also revealed the presence of AQP8 mRNA in the lenticular anterior capsule. The results of immu- 
nohistochemical staining were comparable to those of RT-PCR and gel electrophoresis. Conclusions: The results of this study indicate the distribution of AQP8 in human LECs. This is the first investigation confirming the presence of AQP8 in human LECs.

(C) 2017 The Author(s)

Published by S. Karger AG, Basel

\section{Introduction}

Reactive oxygen species (ROS) are generated during metabolism in cells. Age-related cataracts are induced by the accumulation of ROS, such as superoxide and hydrogen peroxide $\left(\mathrm{H}_{2} \mathrm{O}_{2}\right)$, in the lens [1-3]. The lens is an encapsulated avascular tissue containing single-layer lens epithelial cells (LECs) that are in contact with the aqueous humor. LECs are the main metabolic part of the lens and respond to aqueous humor insults. LECs have been reported to be the primary targets of oxidation in the aqueous humor [4]. Oxidative stress in the aqueous humor causes LEC toxicity and thus contributes to oxidation-induced cataractogenesis.

The aquaporins are a group of small membrane proteins that transport water and several small molecules. Aquaporin 8 (AQP8) facilitates the diffusion of $\mathrm{H}_{2} \mathrm{O}_{2}$ across cell membranes [5]. We previously reported an increase of $\mathrm{H}_{2} \mathrm{O}_{2}$ in the aqueous humor of females with cataracts when superoxide scavenging activity was increased [6]. Therefore, it is necessary to determine how $\mathrm{H}_{2} \mathrm{O}_{2}$ in the aqueous humor changes the oxidative status of the lens. AQP8 in the anterior capsule of the lens may also function as a channel that regulates the influx of $\mathrm{H}_{2} \mathrm{O}_{2}$ from the aqueous humor. In this study, the localization of AQP8 was confirmed by immunohistochemical staining. This is the first study to confirm the location of AQP8 in the human lens.

\section{Materials and Methods}

Samples consisted of central pieces of the anterior capsule, including LECs, measuring $5 \mathrm{~mm}$ in diameter that were collected via continuous curvilinear capsulorhexis during surgery of patients with cataracts. Informed consent according to the tenets of the Declaration of Helsinki was provided and approval from the institutional human experimentation committee was granted. The anterior capsule samples were divided and used for immunohistochemical staining and gel electrophoresis of real-time polymerase chain reaction (RT-PCR) products. The anterior capsule samples for immunohistochemical staining were fixed with $0.75 \%$ paraformaldehyde immediately after collection and stored at $4^{\circ} \mathrm{C}$ until staining. The samples were incubated with anti-AQP8 antibody (ab77198, Abcam) at $4^{\circ} \mathrm{C}$ overnight followed by goat antimouse IgG H and L (Alexa Fluor ${ }^{\circledR} 488$, Abcam) as a secondary antibody providing green fluorescence for visualization. Nuclei were stained with DAPI. The stained samples were observed with a confocal laser-scanning microscope (FV1200 IX83, Olympus).

The anterior capsule samples for RT-PCR and gel electrophoresis were frozen immediately after collection and stored at $-80^{\circ} \mathrm{C}$ until analysis. The RNA was purified with the MagNa Pure Compact RNA Isolation Kit (Roche) after homogenization and proteolyzed using MagNa Lyser Green Beads (Roche). Using a Transcriptor High Fidelity cDNA Synthesis Kit (Roche), cDNA was reverse transcribed by the Gene Amp PCR system 9700 (AB). cDNA of the control RNA (both positive and negative control RNAs included in the kit) was also reverse transcribed at the same time. Using this cDNA, Universal ${ }^{\circledR}$ Probes (Roche) and primers (Nihon Gene Research Inc.), the mRNAs of AQP8 and the internal control, $\beta$-actin, were measured by Applied Biosystems 7500 (Roche) for RT-PCR. The RT-PCR was reacted in a 3-stage cycle: $50^{\circ} \mathrm{C}$ for $2 \mathrm{~min}, 95^{\circ} \mathrm{C}$ for $10 \mathrm{~min}$, and the third stage had two steps, $95^{\circ} \mathrm{C}$ 

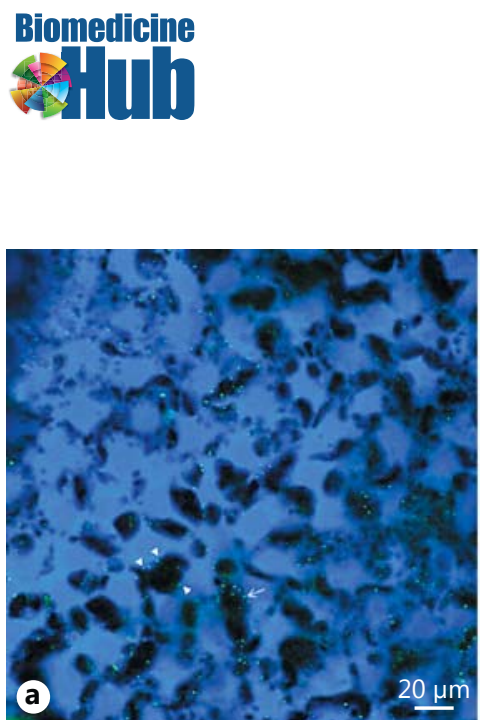

Fig. 1. The distribution of aquaporin 8 (AQP8) labelling. a AQP8 labeling (green) distributed throughout the whole area of the anterior capsulotomy. The cell membrane could not be seen in this fluorescent image because the cell membrane cannot be stained with fluorescent stain or DAPI. AQP8 labeling surrounds the empty area where the cells dropped out. This indicates the localization of AQP8 in the cell membrane of lenticular epithelial cells (LECs). b Nuclei stained by DAPI and AQP8 labeling (green) are observed within LECs $(1,000 \times$ magnification) suggesting AQP8 is distributed in the cytoplasm of LECs. c AQP8 labeling (green) is distributed around the edge of the anterior capsulotomy. Arrow indicates the edge of the anterior capsulotomy. Double arrow indicates the empty space caused by capsulorhexis.

for $15 \mathrm{~s}$ and $60^{\circ} \mathrm{C}$ for $1 \mathrm{~min}$. The expression levels were evaluated at the second step of the third stage in each cycle. The RT-PCR products collected at the end of the 50 cycles were analyzed by $4 \%$ agarose gel electrophoresis at $100 \mathrm{~V}$ for $90 \mathrm{~min}$ followed by densitometric analysis of band density.

\section{Results}

Immunohistochemical staining indicated the AQP8 distribution (Fig. 1). The cell membrane could not be seen in this fluorescent image because the cell membrane cannot be stained with DAPI. However, AQP8 labeling surrounded the empty area where the cells had dropped out (Fig. 1a). Under 1,000× magnification, AQP8 labeling was observed within LECs (Fig. 1b). AQP8 labeling was distributed throughout the whole area and up to the edge of the anterior capsulotomy (Fig. 1c).

The results of the band density of gel electrophoresis and immunohistochemical staining are shown in Figure 2. AQP8 mRNA was present in the samples with dense AQP8 labeling and in the positive control. However, AQP8 mRNA was below the detectable level in the samples with sparse AQP8 labeling and the negative control.

\section{Discussion}

Aquaporins are distributed throughout tissues and have an important role in maintaining water homeostasis and modulating various physiological and pathological processes [7].

The transport properties of AQP8 appear to be species dependent and its cellular and subcellular localization varies among tissues. A study by Elkjaer et al. [8] in rats demonstrated AQP8 was present in the intracellular vesicles of the kidney and subapical parts of the surface epithelial cells of the airways, intestine, and colon. This suggests AQP8 is involved in intracel- 
(C) 2017 The Author(s). Published by S. Karger AG, Basel www.karger.com/bmh

Hayashi et al.: Immunolocation of Aquaporin 8 in Human Cataractous Lenticular Epithelial Cells

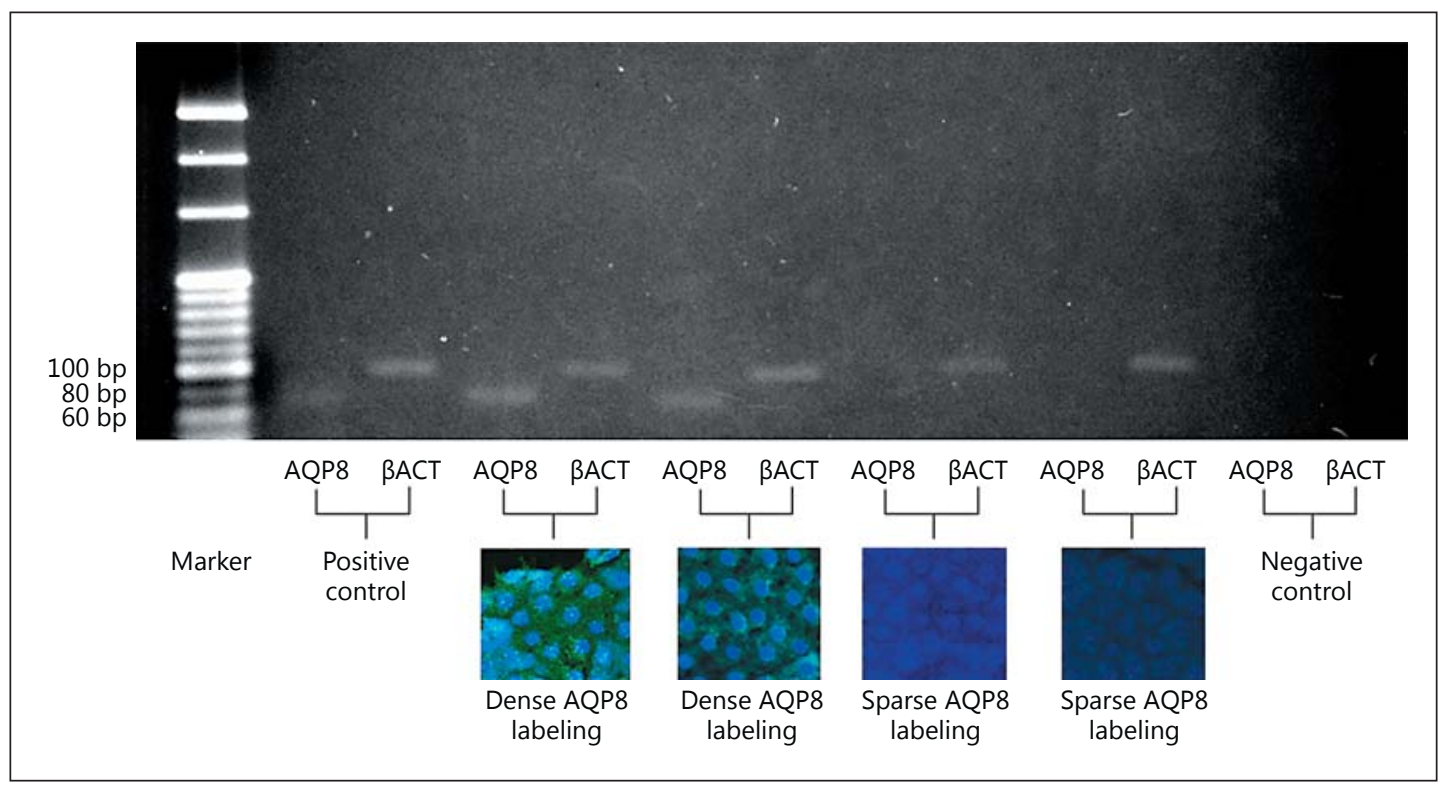

Fig. 2. The correlation between immunohistochemical staining and gel electrophoresis of polymerase chain reaction products. The band density of gel electrophoresis was comparable to the results of immunohistochemical staining. Aquaporin 8 (AQP8) mRNA was present in samples with dense AQP8 labeling and the positive control. In samples with sparse AQP8 labeling and the negative control, AQP8 mRNA was below the detectable level. Upper column shows gel electrophoresis and the lower column shows immunohistochemical staining.

lular water transportation and maintaining the osmotic equilibrium. The presence of AQP8 within LECs suggests it might also have a role in maintaining the osmotic equilibrium in LECs.

AQP8 also facilitates the passage of $\mathrm{H}_{2} \mathrm{O}_{2}$ across the plasma membrane $[5,9]$ and affects the downstream redox signaling pathway mediated by $\mathrm{H}_{2} \mathrm{O}_{2}$ [10]. AQP8 expression was also reported in the inner mitochondrial membranes [11]. This supports the idea that AQP8 facilitates the release of $\mathrm{H}_{2} \mathrm{O}_{2}$ from mitochondria and that defects of AQP8 induce ROS-related depolarization and cell death [12]. The results of the current study suggest that AQP8 may also have a role in the transportation of $\mathrm{H}_{2} \mathrm{O}_{2}$ through the cell membrane of LECs and the movement of $\mathrm{H}_{2} \mathrm{O}_{2}$ among intracellullar compartments of LECs as in other tissues.

The normal lens contains several antioxidant and enzyme systems, such as catalase, to guard against ROS. The inactivation of catalase altered the oxidation-reduction balance in the lens and stimulated lens opacification [13]. Several studies have supported the intracellular and intercellular signaling function of $\mathrm{H}_{2} \mathrm{O}_{2}[14,15]$. The synthesis of catalase in LECs was reported to be dependent on the concentration of $\mathrm{H}_{2} \mathrm{O}_{2}$ [16]. It was also reported that $\mathrm{H}_{2} \mathrm{O}_{2}$ activates the expression of glutathione peroxidase, an inactivator of $\mathrm{H}_{2} \mathrm{O}_{2}$ [17]. Interestingly, during inflammatory colitis, an increase in glutathione peroxidase with a decrease in AQP8 was reported [18]. These changes, which both occurred after an increase in $\mathrm{H}_{2} \mathrm{O}_{2}$, were suggested to be important during intestinal inflammation. The current study demonstrated the presence of AQP8 in LECs suggesting it might also be involved in processes that modulate anti-oxidation by $\mathrm{H}_{2} \mathrm{O}_{2}$ signaling pathways.

In this study, the distribution of AQP8 in LECs collected during cataract surgery was demonstrated by immunohistochemical staining. Furthermore, the expression of AQP8 mRNA was also revealed by gel electrophoresis of RT-PCR products from the same samples. As the first stage of protein synthesis is initiated by mRNA transcription, the presence of 
AQP8 in LECs is supported by the finding that the densities of AQP8 labeling were comparable to the AQP8 mRNA expressions. The results of this study confirmed the localization of AQP8 in the human lens.

\section{Statement of Ethics}

Informed consent according to the tenets of the Declaration of Helsinki was provided and approval from the institutional human experimentation committee was granted.

\section{Disclosure Statement}

The authors report no conflicts of interest. The authors alone are responsible for the content and writing of the paper.

\section{References}

1 Obara Y: The oxidative stress in the cataract formation. J Jpn Ophthalmol Soc 1995;99:1303-1341.

-2 Lin J: The association between copper ions and peroxidative reaction in diabetic cataract. J Jpn Ophthalmol Soc 1996;100:672-679.

-3 Truscott RJ: Age-related nuclear cataract-oxidation is the key. Exp Eye Res 2005;80:701-725.

-4 Spector A: Oxidative stress-induced cataract: mechanism of action. FASEBJ 1995;9:1173-1182.

5 Bienert GP, Moller AL, Kristiansen KA, Schulz A, Moller IK, Schjoerring JK, Jahn TP: Specific aquaporins facilitate the diffusion of hydrogen peroxide across membranes. J Biol Chem 2007;282:1183-1192.

6 Hayashi R, Hayashi S, Arai K, Sakai M, Okamoto H, Chikuda M: The gender-differentiated antioxidant effects of a lutein-containing supplement in the aqueous humor of patients with senile cataracts. Exp Eye Res 2014;129: $5-12$.

7 Agre P, Bonhivers M, Borgnia MJ: The aquaporins, blueprints for cellular plumbing systems. J Biol Chem 1998; 273:14659-14662.

8 Elkjaer M, Nejsum N, Gresz V, Kwon T, Jensen U, Frokiaer J, Niesen S: Immunolocalization of aquaporin-8 in rat kidney, gastrointestinal tract, testis, and airways. Am. J Physiol Renal Physiol 2001;281:F1047-F1057.

-9 Medraño-Fernandez I, Bestetti S, Bertolotti M, Bienert GP, Bottino C, Laforenza U, Rubartelli A, Sitia R: Stress regulates aquaporin-8 permeability to impact cell growth and survival. Antioxid Redox Signal 2016;24:10311044.

10 Vieceli Dalla Sega F, Zambonin L, Fioretini D, Rizzo B, Caliceti C, Landi L, Hrelia S, Prata C: Specific aquaporins facilitate Nox-produced hydrogen peroxide through plasma membrane in leukaemia cells. Biochim Biophys Acta 2014;1843:806-814.

11 Calamita G, Ferri D, Gena P, Cavalier A, Thomas D, Svelto M: The inner mitochondrial membrane has aquaporin-8 water channel and is highly permeable to water. J Biol Chem 2005;280:17149-17153.

-12 Marchissio MJ, Frances DEA, Carnovale CE, Matinelli RA: Mitochondrial aquaporin-8 knockdown in human hepatoma HepG2 cells causes ROS-induced mitochondrial depolarization and loss of viability. Toxicol Appl Pharmacol 2012;264:246-254.

13 Zigman S, Schultz JB, Schultz M: Measurement of oxygen production by in vitro human and animal lenses with an oxygen electrode. Curr Eye Res 1998;17:115-119.

14 Pelle E, Mammone T, Maes D, Frenkel K: Keratinocytes act as a source of reactive oxygen species by transferring hydrogen peroxide to melanocytes. J Invest Dermatol 2005;124:793-797.

15 Waghray M, Cui Z, Horowitz JC, Subramanian IM, Martinez FJ, Toews GB, Thannickal VJ: Hydrogen peroxide is a diffusible paracrine signal for the induction of epithelial cell death by activated myofibroblasts. FASEB J 2005;19:854-856.

16 Gajjar D, Patel D, Alapure B, Praveen MR, Patel A, Johar K Sr, Vasavada AR: Rapid action of oestradiol against hydrogen peroxide-induced oxidative stress in cataractous lens epithelium: an in vitro study. Eye 2009;23: 1456-1463.

17 Avsian-Kretchmer O, Gueta-Dahan Y, Lev-Yadun S, Gollop R, Ben-Hayyim G: The salt-stress signal transduction pathway that activates the gpx1 promoter is mediated by intracellular $\mathrm{H}_{2} \mathrm{O}_{2}$, different from the pathway induced by extracellular $\mathrm{H}_{2} \mathrm{O}_{2}$. Plant Physiol 2004;135:1685-1696.

18 Te Velde A, Pornk I, de Kort F, Stokkers PCF: Glutathione peroxidase 2 and aquaporin 8 as new markers for colonic inflammation in experimental colitis and inflammatory bowel diseases: an important role for $\mathrm{H}_{2} \mathrm{O}_{2}$ ? Eur J Gastroenterol Hepatol 2008;20:555-560. 